\title{
Too enthusiastic to care for safety: Present status and recent developments of nanosafety in ASEAN countries
}

\author{
Md. Ershadul Karim a,*, Abu Bakar Munir ${ }^{\text {a,b }}$, Ahmed Wasif Reza ${ }^{c}$, Firdaus Muhammad-Sukki ${ }^{\text {d,e }}$, \\ Siti Hajar Mohd Yasin ${ }^{\text {f }}$, Siti Hawa Abu-Bakar ${ }^{\text {d,g }}$, Ruzairi Abdul Rahim ${ }^{\text {h }}$ \\ a Faculty of Law, University of Malaya, 50603 Kuala Lumpur, Malaysia \\ ' University of Malaya Malaysian Centre of Regulatory Studies (UMCoRS), University of Malaya, 59990, Jalan Pantai Baru, Kuala Lumpur, Malaysia \\ c Department of Electrical Engineering, Faculty of Engineering University of Malaya, 50603 Kuala Lumpur, Malaysia \\ ${ }^{d}$ School of Engineering \& Built Environment, Glasgow Caledonian University, 70 Cowcaddens Road, Glasgow, G4 OBA Scotland, UK \\ ${ }^{e}$ Faculty of Engineering, Multimedia University, Persiaran Multimedia, 63100 Cyberjaya, Selangor, Malaysia \\ ${ }^{f}$ Faculty of Law, Universiti Teknologi MARA, 40450 Shah Alam, Malaysia \\ g Universiti Kuala Lumpur British Malaysian Institute, Batu 8, Jalan Sungai Pusu, 53100 Gombak, Selangor, Malaysia

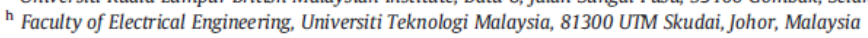

A R T I C LE I N F O

\section{Article history:}

Received 7 March 2014

Accepted 9 July 2014

Available online 12 August 2014

\section{Keywords:}

Nanotechnology

Occupational health and safety

Nanosafety

Risk assessment

Safe handling of nanoparticle

Nanotechnology in Asia

\section{A B S T R A C T}

Nanotechnology has the prospect to vibrate the imagination of human being and has the ability to be used in almost every sector of human need. With its limitless potentials, there are many environmental, health and safety related concems due to extremely ambivalent effects of nanoparticles. Studies revealed that nanoparticles can enter the human body through the lungs, intestinal tract, and skin. Therefore, the researchers and workers who handle nanoparticles and nanomaterials can theoretically and primarily be affected, whereas on the consumers this will have secondary effects. This paper aims at sharing and evaluating the investment scenario, present status and recent developments in nanotechnology, with specific focus on nanosafety issues in different research projects and national nanotechnology policies, strategies or roadmap in 6 ASEAN countries i.e. Indonesia, Malaysia, Philippines, Singapore, Thailand and Vietnam. In general, it can safely be inferred that like their western counterparts, though these ASEAN countries have realized the importance of investment and institutional set-ups, and already spent huge amount of money in nanotechnology, the concern for nano risk and safety is not still considered a serious issue for them. This paper provides a better understanding and highlights the importance of prioritizing nanosafety issue to the policymakers and the stakeholders of this region.

(c) 2014 Elsevier Inc. All rights reserved.

Abbreviations: ANF, Asia Nano Forum; ASEAN, Association of South East Asian Nations; CoE, Center of Excellence; DOST, Department of Science and Technology; EDB, Economic Development Board; EHS, Environmental health and safety; EU, European Union; ICON, Industry Consortium on Nanoimprint; ICON, International Council on Nanotechnology; IEC, International Electrotechnical Commission; IOM, Institute of Occupational Medicine; IRPA, Intensification of Priority Research Areas; ISO, International Organization for Standardization; LPI, Research Center for Physics of Indonesian Institute of Sciences; MDGs, UN Millennium Development Goals; MOSTI, Ministry of Science, Technology and Innovation; NANOTEC, National Nanotechnology Center; NICT, Nanosafety Information Center of Thailand; NIOSH, National Institute for Occupational Safety and Health; NKEA, National Key Economic Areas; NND, National Nanotechnology Directorate; NNI, National Nanotechnology Initiative; NRDA, Nanotechnology Regulatory Document Archive; NSTDA, National Science and Technology Development Agency; NTU, Nanyang Technological University; NUS, Singapore National University; OECD, Organisation for Economic Co-operation and Development; R \& D, research and development; REACH, Registration, Evaluation, Authorisation and Restriction of Chemicals; SHTP, Saigon Hi Tech Park; TC, Technical Committees; UN, United Nations; UNESCO, United Nations Educational, Scientific and Cultural Organization; UNITAR, United Nations Institute for Training and Research; USA, United States of America; USPTO, United States Patent and Trademark Office

* Corresponding author. Tel.: +6018218 2817.

E-mail address: ershad@siswa.um.edu.my (M.E. Karim). 


\section{Introduction}

Nanotechnology, the science of manipulating, modifying and utilizing objects at the atomic level, has the potential to solve many existing problems of the developing countries. The wave of the future, nanotechnology is no more terra incognita, it is no more an agenda of scientists only, rather it has turned into a multi-disciplinary study. The United Nations (UN) Task Force on Science, Technology and Innovation (part of the process designed to assist UN agencies in achieving the United Nations Millennium Development Goals (MDGs)) addressed the potential of nanotechnology for sustainable development and for the betterment of 5 billion people of the developing countries. It was further discussed on how nanotechnology can assist the developing countries in achieving these goals. Sharing the findings of Salamanca-Buentello et al. (2005), the United Nations Educational, Scientific and Cultural Organization (UNESCO) reiterated the top ten applications of nanotechnology within the UN MDGs, which are (UNESCO, 2006): (a) energy storage, productions and conversion; (b) agricultural productivity enhancement; (c) water treatment and remediation; (d) disease diagnosis and screening; (e) drug delivery systems; (f) food processing and storage; ( $\mathrm{g}$ ) air pollution and remediation; (h) construction; (i) health monitoring, and (j) vector and pest detection and control.

Its limitless potentials lure most of the countries to continuously invest huge amount of money in its research and development (R \& D) program. Starting from mid-1990s (Fairbrother and Fairbrother, 2009), the latest data from the Project on Emerging Nanotechnologies developed by the Woodrow Wilson International Center for Scholars shows that more than 1600 consumer products manufactured using nanomaterials are already in the market (PEN, 2014). International Labour Organization (ILO) predicts that by the year 2020 , approximately $20 \%$ of all goods manufactured around the world will be developed based on nanotechnology (ILO, 2010). Besides, the prospect of nanotechnology has been projected in a number of reports released by popular market research companies like Lux Research, Cientifica, BCC Research Market and also many government reports.

It is a matter of fact that in the absence of any specific legal framework nationally and internationally to regulate nanotechnology, the issue of risk and safety is crucial in the development of nanotechnology. If this issue cannot be settled with considerable satisfaction of the consumers and the workers/researchers, it may have to embrace a similar situation like the genetically modified food or nuclear energy, etc., which were initiated to introduce with huge expectations but could not be completely successful in meeting the demand.

Asia, the largest and most populous continent of the world, is very lucrative to the multinationals due to the availability of cheaper labor market. India and China can be the world's producers of nanoenabled products; Japan, South Korea, Taiwan, Singapore, Iran, Turkey, and Hong Kong are known and powerful players in nanotechnology research. The Association of South East Asian Nations (ASEAN), the eighth largest economy in the world, is a geo-political and treaty based organization of ten Asian economies i.e. Brunei, Indonesia, Malaysia, Myanmar, Philippines, Singapore, Thailand, Cambodia, Laos, and Vietnam. ASEAN comprises of $4,435,624 \mathrm{~km}^{2}$, with 616,632 thousand people (ASEANStat, 2013). It has a Gross Domestic Product
(GDP) growth of 5.7\% in 2012 (ASEANStat, 2013). This region is also a very popular tourist destination as every year 85,464 thousand visitors visit this part of the world (ASEANStat, 2013), and the region is very important in terms of nanotechnology R \& D due to some distinctive attributes which is discussed in details in the later part. ${ }^{1}$

The new century began with lots of enthusiasm and inspiration as some of the Asian countries like Japan and China started their nano venture officially since 2001 - in line with their western counterpart - through national nanotechnology policy or strategy. The Republic of Korea, Taiwan, Thailand and Vietnam followed Japan and China immediately. Singapore, Malaysia and Indonesia are the newest entry in the list of Asia Pacific nations (Liu, 2009). However, Singapore even started its nanotechnology journey from 1995, which evolved around the National University of Singapore. To add to this discussion, it will be interesting to share here that over the period of time nanotechnology has attracted people from this region and it is turning to be a matter of interest for the people, which is reflected in the Fig. 1. This figure clearly shows the interest of Asia with nanotechnology and three of the countries from this Fig. 1, i.e. Singapore, Malaysia and Philippines will be considered in this paper.

All these issues inspire the authors to examine the government policy or regulatory setup to handle the risks and safety aspects of nanotechnology in these countries. To this end, focus should be given on various issues including the nanotechnology strategy paper, initiatives taken by the governments, the existing occupational health and safety laws, and the performance of the national bodies e.g. Health Administration, Food and Drug Authority, Department of Labor, and Department of Standard, among others, in this regard. To gather ideas on these issues, this paper is divided into three main segments alongside with the introduction and conclusion. Initially, the findings related to risk and safety published in leading academic journals are presented. After that, an evaluation of the investment scenario, nanotechnology framework, national nanotechnology strategies, policies or roadmaps of these 6 ASEAN countries, highlighting the issue of nanosafety considered in their strategies or policy papers will be made. Finally, based on the developments of other parts of the world, some suggestions will be shared at the end of the paper.

\section{Risk and safety concerns with nanotechnology}

The risk and safety concerns of nanotechnology are almost contemporary with the emergence of it. However, it is a matter of fact that in order to share different kinds of risk and safety issues associated with nanotechnology, the phrase 'nanosafety' is used which is not defined by any authority, rather it is used as the title of some projects and then gained the popularity e.g. EU NanoSafety Cluster. This phrase is commonly used by many people to refer to different issues relating to safety of nanomaterials and nanotechnology. The

\footnotetext{
${ }^{1}$ Pertinent to mention here that this paper has no connection with the ASEAN as an organization and the word "ASEAN" in the title of the paper was
} selected to share an idea of the content of the paper with the readers only. 


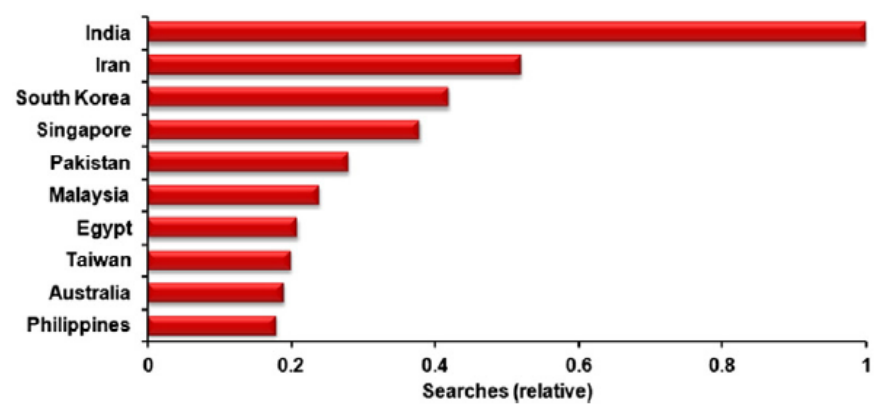

Fig. 1. Search of the term nanotechnology in top ten regions between 2004 and 2012. Adapted from Rogers et al. (2013).

concept of 'safety' is again different from disciplines to disciplines. For the purpose of this paper, 'nanosafety' is used to mean all kinds of risks and safety issues relating to nanoparticles, noting that the evolving definition of nanosafety globally in scientific research communities and under law is an emerging issue in itself.

Organisation for Economic Co-operation and Development (OECD) identified seven types of risks associated with nanotechnology, i.e. (a) business risks, due to marketing of products; (b) intellectual property protection risks; (c) political risks due to economic development of countries; (d) privacy risks due to unlimited sensors; (e) environmental risks due to nanoparticle release; (f) safety risks of workers and consumers; and (g) futuristic risks e.g. human enhancement and self replicator (Lauterwasser, 2005). A plain look at the publications on nanotechnology allows us to conclude that the benefits, risks and safety concerns of nanotechnology are parallel. One of the main reasons behind this concern is that the nanoparticle in between 1 and $100 \mathrm{~nm}$ scale reacts dramatically which is not evident in its bulk form. In a number of research, both in vivo and in vitro, it has been confirmed that nanoparticles can enter the human body through the lungs, the intestinal tract, and skin (Hoet et al., 2004; Radad et al., 2012; Poland et al., 2008; Yah et al., 2012) and even to unborn baby from pregnant worker mother (Takeda et al., 2009). Even after continuous assurance from the companies and governments (Becker, 2013), some people are still considering nanoparticle as the next asbestos (Carter, 2008; Grimshaw et al., 2011; Matsuda and Hunt, 2009; UNESCO, 2006). Though it is not yet the right time to conclude if the nanotechnology-enabled products are harmful to human health, most of the research already warned the researchers and workers about this risk due to their close propensity with nanoparticles or nanomaterials (Albrecht et al., 2006). In fact, it is suggested that they are more in a danger zone than the consumers (Albrecht et al., 2006). It has already been reported that seven workers in a Chinese paint factory that was using nanotechnology were suffered from permanent lung damage where two of them died (Lyn, 2009). Interestingly, although the Chinese government denied the fact, the doctors who treated these workers ruled in favor (Song et al., 2009). The team of doctors concluded that long-term exposure to some nanoparticles without protective measures may lead to serious damage to lungs and it is impossible to remove nanoparticles that have penetrated the cells. Besides, studies revealed that carbon nanotubes, when directly injected into the lungs of mice, could damage lung tissue (Mongillo, 2009), cause scarring (Carter, 2008), etc.

Even with such predictions and findings, companies dealing with nanomaterials are reluctant to consider this issue seriously (Becker, 2013). Helland et al. (2007) emphasized on voluntary risk assessment initiatives adopted by different companies and surveyed 40 companies in Germany and Switzerland. They found that around $65 \%$ of the companies did not perform any risk assessment of their nanomaterials and for $32.5 \%$ of them, although they did carry out some risk assessment, it was not practiced regularly i.e. sometimes the companies conducted risk assessment and sometimes they did not.

The database of the Project on Emerging Nanotechnologies developed by the Woodrow Wilson International Center for Scholars has also listed the products according to potential exposure pathways into the human body. It is claimed that the product can be exposed to human bodies by four ways dermal, ingestion, inhalation, and oral. Though it was further claimed that the products are not tested to verify if there is any actual risk for human exposure or toxicity, the listing of these products and categorization are sufficient to be warned. Of the total 1600 plus consumer products, 422 products can enter the human body -218 products can enter the human body through dermal, 96 products by way of injection, 42 products by way of inhalation, and 66 products can enter orally. It is a matter of concern that a good number of products from these 422 products are manufactured in Japan, Korea and China (PEN, 2014). From the regulatory point of view, listing of these four ways as the possible route to human exposure gives clue to draw conclusions that the laws governing nanorisk and safety should consider these in the black letters of law.

Simultaneously, the concern of existing occupation health and safety and regulatory adequacy have been shared in a number of previous research (Munir and Mohd Yasin, 2007; Munir and Mohd Yasin 2008; Savolainen et al., 2010; Schulte and Salamanca-Buentello, 2007). The importance of consideration of occupational health and safety in the development of sustainable and responsible nanotechnology was considered by lavicoli et al. (2009). However, it is a matter of great concern that this issue is still overlooked even though the concern has been expressed in a number of commissioned 


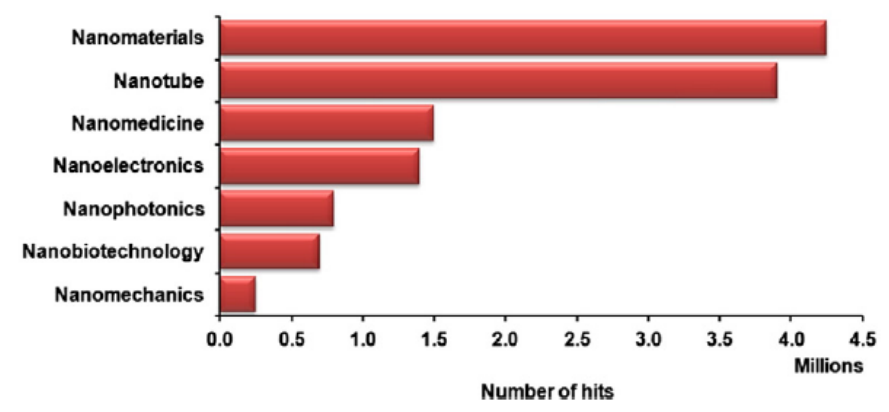

Fig. 2. Googling Nano on May 24, 2012. Adapted from Rogers et al. (2013).

research conducted by individuals, organizations and government authorities.

Rogers et al. (2013) shared the statistics of Google on what people search regarding nanotechnology on May 24, 2012, and the data is presented in Fig. 2. This figure reflects that Google users were not accustomed to with the findings of researchers on nanorisk or they did not have much interest on safety issues relating to nanomaterial or nanoparticles, or in another way it can be interpreted that comparatively a small number of the stakeholders search for information on nanosafety and risk. To add to this finding, Tanthapanichakoon et al. (2013a) analyzed and compared journal statistics of selected ASEAN countries including Japan, Singapore, Thailand, Malaysia, Vietnam and Indonesia from Science Direct between 2001 and January 2013 and classified the published papers in different heading - but the issue of risk and safety was not considered. Almost similar findings are shared by Tanthapanichakoon et al. (2013b), when they considered the publications of Science Direct between 2006 and March 2012. It was revealed that Singapore has experts in a wide range of the nanotechnology field and applications i.e. carbon materials, biosensors, bioelectronics and pharmaceuticals, Malaysia has interest on alloys and compounds along with carbon materials, and separation technology, Thailand puts focus on molecular modeling, carbon materials and, biosensor and finally classified 612 papers in different categories - but again, failed to classified the safety and risk issues. These reiterate the importance of revisiting the issue of risk and safety in ASEAN context.

\section{Nanotechnology development and risk and safety initiatives in ASEAN countries}

This paper is developed mainly on secondary sources collected from the websites of government bodies or nanotechnology authorities of the six ASEAN countries. These countries are selected based on the records as compiled in the Iranian National Statistics page on nanotechnology, StatNano (INIC 2014) and the patent information from the United States Patent and Trademark Office (USPTO), which is also included in the StatNano website. Only 6 ASEAN countries i.e. Indonesia, Malaysia, Philippines, Singapore, Thailand and Vietnam are considered and for the obvious reasons of non-availability of a considerable amount of information. This paper does not consider nanotechnology development in the context of Brunei, Myanmar, Cambodia and Laos PDR.
Nanotechnology Regulatory Document Archive (NRDA) developed by the Arizona State University was consulted and no documents for these countries could be found except one single document on Thailand (ASU, 2014). Azonano (2014) developed a list of suppliers from countries around the world and the latest data shows that from the ASEAN region, Singapore is the leading country with 24 suppliers, Malaysia and Thailand have 5 suppliers each, 3 suppliers are listed from Vietnam and 1 from Indonesia. There is no supplier from five other member states of ASEAN i.e. Brunei, Cambodia, Myanmar, Philippines and Laos PDR. Whereas the database of Project on Emerging Nanotechnologies developed by the Woodrow Wilson International Center for Scholars indicated 4 products from Thailand, 24 products from Singapore, 1 from the Philippines and 4 from Malaysia (PEN, 2014). All these findings guide us to confine our focus only on these six countries.

The latest Human Development Index based on three basic dimensions of human development i.e. long and healthy life, knowledge and descent standard of leaving released by the UNDP, Singapore with 0.895 points [18th in world ranking] and Malaysia with 0.769 points [64 in world ranking] are listed as high human development country, Thailand with 0.69 points [ranked 103] and Philippines with 0.654 points [ranked 114] are listed as medium human development country, Indonesia with 0.629 points [position 121] and Viet Nam with 0.617 points [position 127] were listed as low human development country (UNDP, 2013). Simultaneously, based on the research publications of 165,020 original articles in ISI indexed journals between 1991 and 2010, Nguyen and Pham (2011) classified Singapore in group one, Thailand and Malaysia in group two, Viet Nam, Indonesia and the Philippines in group three with medium number of publications and the rest four countries of ASEAN i.e. Cambodia, Laos, Myanmar and Brunei were placed in group four with lowest number of publications. Interestingly, this categorisation also reflects that these 6 countries primarily give due attention to scientific development.

It has been shared initially that these 6 ASEAN countries have taken many initiatives towards achieving a leading position in nanotechnology R \& D and have already adopted some strategies relating to nanotechnology and most of these strategies include safety related provisions. The summary of the findings in this section is presented in Table 1. Besides, these countries are members of some of the nanosafety related international standard setting organsations e.g. OECD Working Party on Nanotechnology, OECD Working Party on 
Table 1

Summary of the initiatives by selected ASEAN countries towards achieving a leading position in nanotechnology R\&D.

\begin{tabular}{|c|c|c|c|c|}
\hline Countries & $\begin{array}{l}\text { ISI publication related to } \\
\text { nano [From 2000-Feb, 2014] } \\
\text { (INIC, 2014) }\end{array}$ & R \& D expenditure & $\begin{array}{l}\text { Patent per } 100 \text { nano- } \\
\text { articles in USPTO } \\
\text { [2009-2013] (INIC, 2014) }\end{array}$ & Policies related to nano \\
\hline Singapore & 14,290 & $\begin{array}{l}\text { SGD } 20 \text { million per annum } \\
\text { (SNG Gek Khim, 2008) }\end{array}$ & 45.44 & - \\
\hline Malaysia & 4407 & MYR 3640 million (MNA, 2012) & 5.87 & National Nanotechnology Statement \\
\hline Thailand & 3202 & $\begin{array}{l}\text { Annual budget of USD } 11 \text { million } \\
\text { (Songsivilai, 2013) }\end{array}$ & 8.12 & $\begin{array}{l}\text { The National Nanotechnology Policy } \\
\text { Framework (2012-2021), } \\
\text { The Nanosafety and Ethics Strategic Plan } \\
(2012-2016) \text {, }\end{array}$ \\
\hline Philippines & 141 & PHP 2.5 billion (Villafania, 2009) & - & Ten Years Nanotechnology Roadmap 2009. \\
\hline Indonesia & 346 & $\begin{array}{l}\text { USD } 100,000 \text { (in 2005) } \\
\text { IDR } 265 \text { billion (in 2010) } \\
\text { (Ariffahmi, 2009) }\end{array}$ & 12.18 & - \\
\hline Vietnam & 1000 & $\begin{array}{l}\text { VND } 5 \text { billion } \\
\text { (Khoi and Minh, 2009) }\end{array}$ & 5.03 & $\begin{array}{l}\text { National Strategy of Science and Technology } \\
\text { Development }\end{array}$ \\
\hline
\end{tabular}

Manufactured Nanomaterials, International Standardization Organization (ISO) Technical Committee (TC) 229 on Nanotechnologies, International Electrotechnical Commission Technical Committee 113 (Nanotechnology Standardization for Electrical and Electronics Products and Systems) and other organisations like Asia Nano Forum (ANF), a network organization of 15 economies in the Asia Pacific region with its headquarter in Singapore. In this segment, the risk and safety issues and research relating to nanotechnology, with references to the respective strategy papers will be the issue of consideration.

\subsection{Singapore}

Singapore is very prospective for nanotechnology investment and its competence in nanotechnology $\mathrm{R} \& \mathrm{D}$ has been projected in a number of research (Hassan et al., 2012; Nguyen and Pham, 2011). The country does not have any national strategy on nanotechnology, albeit it has already been acclaimed by the OECD that it is specialized on nanotechnology related patenting activity. In fact, during 2004-2006 period, the country obtained nearly three times the average share of all nanotechnology patents (OECD 2009). By initiating such endeavors, the country has established a new trend to achieve global leadership even without broad national nanotechnology policy (Matsuura, 2006).

The country is the member of OECD Working Party on Manufactured Nanomaterials, ANF, ISO TC 229, IEC/TC on Nanotechnology. There is a working group for ISO/TC 229 and IEC/TC 113 on Nanotechnology under the Chemical Standards Committee of the National Standardization Program.

It has been estimated that 750 researchers in the National University of Singapore and 90 faculty members in Nanyang Technological University (NTU) are actively involved in nanotechnology research. The industry in the country has been growing at a rate of about $8 \%$ to $21 \%$, and the number of companies dealing with nanomaterials increased by three times in the last three years. With the current number of 41 companies, the country spends SGD 20 million per annum for R \& D and human resource development in Nanotech (SNG Gek Khim, 2008). Singapore Economic Development Board (EDB Singapore) estimated that there are 50 companies and 1000 researchers, scientists and engineers are currently working in Nanotech industries. The Nanoscience \& Nanotechnology Initiative of Singapore National University (NUSNNI), established in January 2002, have been investigating the environmental and health implication of gold nanoparticle using in vitro model, but there has not been any research yet on human health and safety aspect (NUS, 2014). There are consortiums and partnership platforms like Industry Consortium on Nanoimprint (ICON) and Nanotechnology in Manufacturing Initiative (NiMI) and some Centers of Excellence like the Singapore Graphene Research Center at NUS and Energy Research Institute at NTU. The Workplace Safety and Health Institute drafted a Research Agenda for Singapore for 2011-2016, where under the category of new technologies, the study of risk management and safety issues relating to nanotechnology was placed under research theme 2 , i.e. research on workplace safety and health risks and solutions. However, it is still a matter of fact that the experts in Singapore are still in favor of concentrating on the benefits and needs than the safety issues compared to the experts in Europe and Australia (Gupta et al., 2013).

Singapore has completed the NanoSafety Survey, which was jointly commissioned by the Ministry of Manpower and EDB Singapore and administered by NanoConsulting (NanoConsulting, 2010). It was found that the country uses a very small amount of nanomaterials, i.e. not even $1 \mathrm{~kg}$, and the organizations which were studied are keen to know more details about nano-specific safety measures. Only $26 \%$ of the respondents claimed to have the availability of the state-ofthe-art nanosafety measures and out of the rest of the respondents, $5 \%$ did not consider the issue of nanosafety as an immediate issue of concern, $16 \%$ did not have enough knowledge on this issue and 53\% were in search of effective nanosafety measures which can be implemented in their company.

\subsection{Malaysia}

Malaysia proclaimed its national vision, i.e. Vision 2020 in 1990 with the goal of attaining the status of a developed nation by the year 2020. To that end, Malaysia aspired to be one of the top 10 nanotech nations and took the initiative in 2001 with a mission for sustainable national development of science, technology, industry and economy (Hashim et al., 
2009). The Intensification of Priority Research Areas (IRPA) program of the Eighth Malaysia Plan, ${ }^{2}$ which is administered by the Ministry of Science, Technology and Innovation (MOSTI), identified nanotechnology as one of the 14 research priority areas. Up to 2005, Malaysia spent more than MYR 140 million IRPA grants on different projects on nanotechnology (TheSunDaily, 2005). ${ }^{3}$ The government allocated MYR 1 billion under the Eighth Malaysia Plan and MYR 2.5 billion under the Ninth Malaysia Plan (MNA, 2012) and intended to increase the amount significantly in the Tenth Malaysia Plan.

With the hope and aspiration to be high income country by the year 2020, the government has identified 12 National Key Economic Areas (NKEAs). Under these 12 NKEAs, till date 159 Entry Point Projects (EPP) were identified, and the "EPP 20: Enabling Industries through nanotechnology" is placed under electrical and electronics industry (E\&E), which is a very significant sector in terms of export. This sector contributed $41 \%$ of Malaysia's total exports in 2009. It is estimated that this EPP 20 will add gross national income of MYR 1247.9 million and will create new job opportunity for 798 people.

The government of Malaysia has established a National Nanotechnology Directorate (NND) and launched the National Nanotechnology Statement (MNA, 2012). Besides, significant advancement in the field of nanotechnology in Malaysia can also be noticed. Around 15 universities established well-equipped nano science centers. The government has also taken National Nanotechnology Initiative (NNI), Malaysia with the vision of "nanotechnology for sustainable national development of science, technology, industry and economy". The government has also incorporated nanotechnology as a national priority in the Ninth Malaysia Plan and proposed the establishment of the National Nanotechnology Centre by the MOSTI (Bernama, 2011). Moreover, the government has published the National Nanotechnology Statement in July 2010 where the Fourth theme in the statement is to 'uphold regulations and acts' relating to nanotechnology.

Hashim et al. (2009) studied the nanotechnology development status in Malaysia from industrial strategy and practices perspective and successfully identified some of the strengths, weaknesses, opportunities and threats of nanotechnology in Malaysia. But it is understood that being scientists, though they shared the prospects of nanotechnology in health and medicine, they did not consider the risk and safety issues relating to nanotechnology. Even though the infrastructure and facilities for nanotechnology are not adequate, seven factors i.e. external forces, human resource, technical issues, internal issues, technology partnership, knowledge and culture influenced the country towards nanotechnology drive (Elley Nadia, 2009).

The Department of Occupational Safety and Health of the Ministry of Human Resources of Malaysia developed a manual of recommended practices in 2000 to assess the health risks arising from the use of hazardous chemicals in the workplace (DOSH, 2000) and suggested 10 steps to follow. However, it should be

${ }^{2}$ Malaysia Plan is an economic plan developed by the Government of Malaysia. It spans for a duration of five years. For example, the Eight Malaysia Plan covered the economic development between 2001 and 2005.

${ }^{3}$ Deputy Prime Minister Datuk Seri Najib Abdul Razak (as he was then) during inauguration of the Malaysia Nanotechnology Forum 2005 and the Annual Fundamental Science Seminar at the Ibnu Sina Institute, University Teknologi Malaysia (UTM). realized that the manual was prepared at a time when the issue of nanotechnology was not in a much developed stage.

Few highly well-equipped nanoscience/nanotechnology research centers were already established in different universities e.g. the Ibnu Sina Institute for Fundamental Science Studies (IIS), Universiti Teknologi Malaysia, Institute of Microengineering and Nanotechnology (IMEN), Universiti Kebangsaan Malaysia, Advanced Materials Research Centre (AMREC) of SIRIM Bhd and the Combinatorial Technology and Catalysis Research Centre (COMBICAT), Universiti Malaya. Though the government has established a number of Centers of Excellence in the country the latest report from the Academy of Sciences of Malaysia reveals that none of the Center of Excellence ( $\mathrm{CoE}$ ) considers the issue of nontoxicity and environmental toxicity and there is no guideline on safe handling of nanomaterials (Akademi Sains Malaysia, 2013).

Pertinent to mention here that the Standards Malaysia, the national department of standards, formed a TC on Nanotechnology and there is also a Working Group on the Health, Safety and Environmental Aspects of Nanotechnologies (WG3) under its Industry Standards Committee (ISC B). The country has participated in the ISO/TC 229 on Nanotechnology and IEC/TC 113. Nanotechnologies Standardization for Electrical and Electronics Products and System (Standards Malaysia, 2009).

\subsection{Thailand}

Thailand can be seen as the ASEAN leader in terms of nanosafety programs since it has taken a number of initiatives and to this end, has already taken strategy, framed different guidelines, established Nanosafety Information Center etc. The government nanotechnology initiative was formally triggered with the visit of former President Thaksin Shinawatra to the National Science and Technology Development Agency (NSTDA) in Thailand Science Part in December 2002 with his order to the authority of the NSTDA to investigate the prospect of establishing a national nanotech center (Tanthapanichakoon et al., 2009).

In 2007, Thailand took a National Strategic Plan for nanotechnology with an allocation of THB 300 million with an intention to earn 1\% of countries GDP i.e. US\$ 3 billion by 2013. Even with huge investment in nanotechnology R \& D, initially shortage of researchers and scientists was identified as problem (Sandhu, 2008). As of 2010, there were seven associate centers with about 400 researchers, with aims, inter alia, to raise health and environmental standards of international levels and to take lead in ASEAN in nano-based education and R \& D.

The cabinet on 11 September 2012 approved the National Nanotechnology Policy Framework (2012-2021) for 10 years with the objectives of enhancing the competitiveness, quality of life and sustainable development and promoting Thailand as a leader in nano-education and nano-research among ASEAN countries. The Ministry of Science and Technology and relevant agencies will be implementing this Policy Framework (MOST, 2012).

In the Policy Framework, the country identified four clusters i.e. health and medicine, food and agriculture, manufacturing industry and energy and environment. There are also eight targeted industries from these four clusters i.e. food and agriculture, electronics, automotive, textile, chemicals/ petrochemicals, health and medicine, SMEs/community and 
energy and environment. The Policy Framework further identified seven products where the country can claim its competence i.e. nanosensors, nanoelectronics, drug delivery system, nanocosmeceuticals, nanocatalysts and Nanofiltration Materials, Nano Coating Materials and Functional Nanostructure. The Policy Framework realized that the issue of management e.g. improvements of quality, standard, safety and ethical system for quality of life and wellness is important to improve the enabling factors at the fundamental level.

The country specified five strategic intents to achieve the three main goals, and the first strategic intent is the utilization of nanotechnology for the improvement of quality of life, health, medicine and public health. In order to ensure this intent, the country set a goal, inter alia, to develop a management system and guidelines for nanosafety and nanotechnology applications. Hence, the strategy was stipulated to provide knowledge and mechanism for nanotechnology in safety, monitoring, ethics and standards. In this regard, (a) efficient mechanisms for the management and dissemination of knowledge on safety and ethics will be provided, (b) the activities of the national committee on nanotechnology safety and ethics will be supported, and (c) the quality control, standards and safety of nanoenabled products will be improved.

The country has established a National Nanotechnology Center (NANOTEC) within the NSTDA, which has boosted up the nanotechnology R \& D in the country (Charinpanitkul et al., 2008; Tanthapanichakoon, 2008). Furthermore, in the Thailand Science Park, there is the NANOTEC Central Laboratory and within this Laboratory, a Nano Safety and Risk Assessment Laboratory was established. Moreover, the Center has been arranging different programs to make citizens aware of nanotechnology and its application with the assistance of the Public Awareness and Training Section of NANOTEC and Teacher Training of Nanotechnology Network (TTN). With such programs, the organizers inform students about different safety aspects of nanotechnology. The NANOTEC, in collaboration with the United Nations Institute for Training and Research (UNITAR), has initiated a pilot project on nanosafety in the country.

The country has further adopted the Nanosafety and Ethics Strategic Plan (2012-2016) (NSTDA, 2012), focusing on three strategies i.e. (a) knowledge creation and management relating to nanosafety and nanoethics, (b) development and improvements of supervision and enforcement mechanisms and (c) promotion of public participation. Before finalizing the plan, the National Nanotechnology Center (NANOTEC) arranged a public hearing session, which is very positive and significant in this region as citizens were included within the process (Dalton-Brown, 2012). The Nanosafety and Ethics Strategic Plan (2012-2016) is summarized in Fig. 3.

The country has already established the Nanosafety Information Center of Thailand (NICT) and further prepared three NanoSafety Guidelines i.e. for (i) factory workers, (ii) university researchers, and (iii) for general public (Tanasugarn, 2012). Apart from these guidelines, there are at least three laws which can be interpreted to consider nanosafety issues, i.e. the Hazardous Substance Act of BE 2535 of AD 1992, the Enhancement and Conservation of National Environmental Quality Act of BE 2535 of AD 1992 and the Labour Protection Act of BE 2541 of AD 1998.
Besides, it has been reported that the country has already introduced a voluntary Nano Mark, i.e. NanoQ a label to inform the customer about the possible existence of nanoparticle and the mark is initially introduced in paint, textile and household products. This is undoubtedly a significant breakthrough in the context of Asia as this will serve multi-purposes for the consumers, manufactures and the regulators. A paint formulation production company named Supreme Products Co. Ltd. was given the first NanoQ Label Certificate on 27 September 2012 for two years and the company will have to renew the certificate after two years. The National Nanotechnology Association will be collecting samples of products from the market to monitor the production of the products. The NanoQ label is illustrated in Fig. 4.

The Food and Drug Administration of the country has released a 61 page booklet on nanosafety in national language with pictures and illustrations for officials, entrepreneurs and academics (FDA, 2011), and Ministry of Industry formulated a Guideline on Safety in Working with Nanotechnology (Tanasugarn, 2012). These are undoubtedly great efforts to make citizens aware of nanotechnology and its associated safety issues in the national language as they are the ultimate stakeholders of nanotechnology.

\subsection{The Philippines}

Of all the 6 countries considered in this paper, the Philippines is the newest member to join the revaluation powered by nanotechnology. It has started its formal move in this regard since 2009 through the adoption of the 10 year Nanotechnology Roadmap. However, it has been reported that in 2003, at least 6 working groups were working on nanotechnology (Maclurcan, 2011). The Department of Science and Technology (DOST) with its concerned agency i.e. the Philippine Council for Advance Science and Technology Research and Development adopted the roadmap with a proposed budget of PHP 2.5 billion and it has attached significant priority on nanotechnology R \& D and formed a multi-disciplinary group.

Being the newest member, the country could spell out emphatically the importance of safety issues relating to nanoparticles or nanomaterials. Five areas for the application of nanotechnology i.e. ICT and semiconductors, energy, agriculture and food, medicine and environment were specified and health and environmental risk were identified with score $(1=$ High and $5=$ Low $)$. For example, while sharing the prospect of nanocatalysts for combustion, smart delivery systems in agriculture and food, nanodiagnostics (in vitro, ex vivo), nanoimaging (in-vivo), nanoprobes (in vivo), it has been identified that the health and environmental risk in these categories are high (score 1). For environmental remediation and treatment, the risk is almost high (score 2), and for food packaging, nanosensors, plant and animal breeding, environmental sensors, green materials (including forest products), the risk is in between high and low (score 3). Moreover, the Nanotechnology Roadmap spells out the importance of health and environmental risk and puts emphasis on public education, public engagement, needs of public, establishment of a nanotechnology clearing house and 


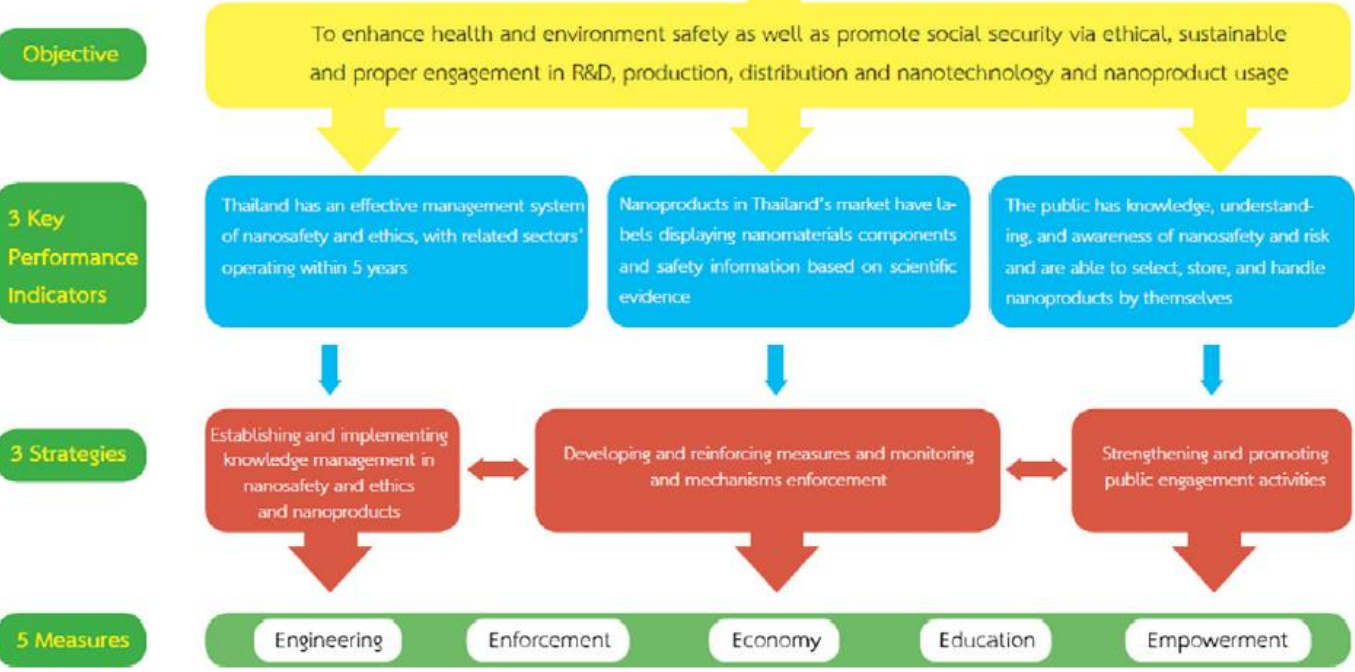

Fig. 3. Thailand's Nanosafety and Ethics Strategic Plan (2012-2016) (NSTDA, 2012).

parallel research on the health and environmental risks of nanotechnology products, life-cycle assessments, and societal impacts. Furthermore, as per roadmap, the country formed one study group on Health and Environmental Risk (Dayrit, 2010). It is obvious that the country is still in its initial stage and even in such stages its realization as to risk and safety identification and forming of the working group are really praiseworthy.

\subsection{Indonesia}

The fourth largest country in the world - Indonesia - was a country in transition when its ASEAN neighbors triggered the nanotech race. In the absence of any government policy or government funding, the nanotechnology venture started

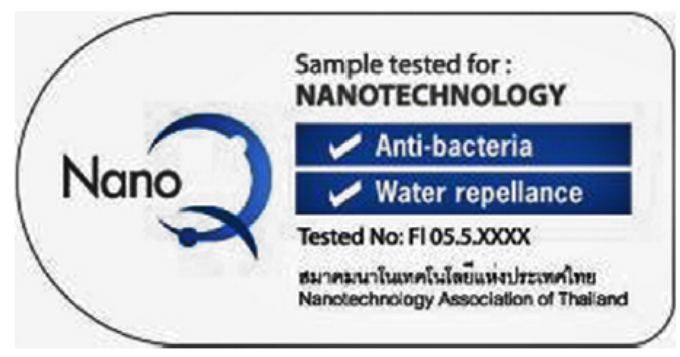

Fig. 4. The NanoQ label (NSTDA, 2011). in Indonesia through universities and research center, e.g. with the University of Indonesia in 2001 (Wahyuni et al., 2011) and later on with the establishment of Indonesian Nanotechnology Profession Society (Masyarakat Nanoteknologi Indonesia), the Indonesian Nanotechnology Profession Society 2005 by the Research Center for Physics of Indonesian Institute of Sciences (LIPI) and State Ministry of Research, Science and Technology of Indonesia. The Mochter Riady Center for Nanotechnology and Bioengineering which was privately established in 2004 has a great contribution in the development of nanotechnology and the government adopted the nanotechnology development roadmap in 2006 (Rochman and Brama, 2009). In 2005, the government allocated USD 100,000 for nanotech R \& D and a good number of research have already been undertaken and obviously the issue of risk and safety with nanotechnology were not a priority and were not considered in any of these projects. Simultaneously, very recently in 2010, the government allocated IDR 265 billion (USD 28 million approx.) for nanotech R \& D. A significant increase in government funding is evident from different statistics. The country undertook a detailed plan and adopted a number of projects for nanotechnology R \& D, however, it can safely be said from reading in the chapter by Rochman and Brama (2009) that the issue of risk and safety is not at all a concern for the country.

\subsection{Vietnam}

Professor Nguyen Van Hieu as the President of Vietnamese Physical Society in 1987 while channeling his dream to

Link to Full-Text Articles : 